\title{
Repensando algumas questões sobre o trabalho infanto-juvenil
}

\author{
Alda Judith Alves-Mazzotti \\ Universidade Estácio de Sá, Mestrado em Educação
}

Embora o trabalho infanto-juvenil ${ }^{1}$ não seja um fato novo, foi somente em meados da década de 1980 que os dados pertinentes à questão, disponíveis nos censos populacionais e nas Pesquisas por Amostra de Domicílios (PNAD), produzidas pelo Instituto Brasileiro de Geografia e Estatística (IBGE), assim como na Relação Anual de Informações Sociais (RAIS) do Ministério do Trabalho, começaram a ser melhor explorados, permitindo realizar comparações entre diferentes faixas etárias, extratos sociais e regiões do país (Cervini e Burger, 1991). A partir de então, inúmeros estudos têm sido produzidos tomando por base aquelas fontes, embora muitas críticas tenham sido feitas a conclusões sobre o trabalho infantil com base naqueles dados. Em ampla revisão da literatura sobre a infância pobre no Brasil, Alvim e Valladares (1988) indicaram que, dos 212 títulos analisados, 112 tomavam

\footnotetext{
${ }^{1}$ Sarti (1999) considera trabalho infantil aquele que é exercido por meninos e meninas de até 14 anos de idade; a denominação "trabalho infanto-juvenil" é usada quando se inclui a faixa dos 15 aos 18. O termo trabalho precoce é aqui utilizado como sinônimo de "trabalho infanto-juvenil".
}

como referência dados provenientes das fontes citadas. Segundo as autoras, por serem coletados com finalidades mais amplas, esses dados nem sempre eram adequados à compreensão das consequências da pobreza na infância, entre as quais se destaca o trabalho infanto-juvenil. Os dados provenientes daquelas fontes, portanto, devem ser usados com cautela e analisados criticamente, como veremos a seguir.

\section{Extensão do trabalho infanto-juvenil}

Segundo dados do Anuário Estatístico do Brasil, relativos a 1999 (IBGE, 2000), 16,9\% das crianças entre 10 a 14 anos e $45,9 \%$ dos adolescentes entre 15 a 17 anos trabalham. Esses percentuais, apesar de muito elevados, subestimam a extensão do problema por várias razões. Primeiro, porque as taxas de atividade apresentadas nos censos e nas PNAD incluem apenas as pessoas que estão trabalhando ou procurando trabalho na semana de referência da pesquisa. $\mathrm{O}$ trabalho infanto-juvenil, entretanto, é tipicamente intermitente, o que faz com que muitas crianças que trabalham 
escapem à contagem por não atenderem àqueles critérios. Outro complicador para a estimativa da extensão desse trabalho é o fato de que a emenda constitucional no 20 , de 15/12/1998, proibiu o trabalho de menores de 16 anos, salvo na condição de aprendiz (a partir dos 14 anos), ${ }^{2}$ o que faz com que o trabalho de crianças e adolescentes com idade inferior seja freqüentemente escamoteado. A tendência dos pais a considerar o trabalho infantil como "ajuda" quando este é exercido juntamente com familiares, estando ou não relacionada a essa proibição, certamente contribui também para minimizar a extensão do fenômeno. Além disso, embora, desde 1992, as PNAD tenham ampliado o conceito de trabalho, passando a incluir, como nova categoria, o trabalho doméstico, este, quando exercido na própria casa, carece de visibilidade, o que faz com que grande parte dessas atividades não seja computada. Finalmente, sabe-se que o trabalho das crianças de menos de 10 anos, na grande maioria dos casos, é exercido na agricultura, em áreas rurais, onde a visibilidade é também precária.

O Censo de 2000 indicou algumas mudanças nesse panorama, uma vez que a renda das famílias brasileiras aumentou, em média, 41,9\% na década de 1990. No entanto, o índice de Gini, ${ }^{3}$ que reflete a desigualdade na distribuição de renda da população, permaneceu praticamente inalterado, passando de 0,637 em 1991 para 0,609 em 2000, o que situa o Brasil entre os quatro países de mais alta desigualdade no mundo. Outro dado significativo presente neste último Censo revela que, entre 1991 e 2000, o número de domicílios brasileiros chefiados por mulheres aumentou $37,5 \%$, passando de $18,1 \%$ para $24,9 \%$. No estado do Rio de Janeiro, por exemplo, esse percentual chega a 35,3\% dos domicílios. Embora esses dados possam, em parte, ser atribuídos à emancipação da mulher e

${ }^{2}$ Pela legislação anterior, o trabalho era permitido a partir dos 14 anos e, na condição de aprendiz, a partir dos 12, conforme consta do Estatuto da Criança e do Adolescente (1991, Cap. V, art. 60).

${ }^{3} \mathrm{O}$ índice de Gini varia de 0 a 1; quanto mais próximo de 1, maior a desigualdade na distribuição de renda da população. ao maior nível de escolaridade alcançado pela população feminina, constata-se que 16,2\% das mulheres chefes de família não têm instrução (nunca freqüentaram a escola ou não terminaram a $1^{\mathrm{a}}$ série do ensino fundamental) e $18,5 \%$ têm entre 1 e 3 anos de escolaridade (O Globo, Retratos do Brasil, 20/12/2001, p. 36). Tendo de assumir sozinhas a responsabilidade pelo sustento da família e apresentando, em sua grande maioria, um nível de escolaridade que não as favorece na disputa por postos de trabalho, essas mulheres tipicamente contam com o trabalho dos filhos para compor o orçamento familiar. $\mathrm{O}$ aumento da renda média das famílias, portanto, é enganoso no que se refere às possibilidades de diminuição do trabalho infanto-juvenil.

\section{Trabalho infanto-juvenil e "fracasso escolar"}

Duas ordens de preocupações motivam os esforços pela erradicação do trabalho infanto-juvenil: as condições de trabalho impostas às crianças e aos adolescentes e os prejuízos causados à escolarização. Essas duas preocupações estão freqüentemente relacionadas na literatura, uma vez que, segundo dados do IBGE (2000), o percentual de jovens que trabalham e estudam é significativo: $10,8 \%$ na faixa de 10 a 14 anos e $22,6 \%$ na de 15 a 17 anos.

No que se refere às condições de trabalho, tem sido verificado que a maioria das crianças trabalha muito e ganha pouco, além de não estar protegida pela legislação trabalhista. Menos de $2 \%$ das crianças entre 10 e 14 anos e $14,9 \%$ das de 15 a 17 tinham carteira assinada, segundo a PNAD de 1995. As jornadas de trabalho eram bastante longas, sobretudo para os adolescentes: 40 horas ou mais para $23 \%$ dos trabalhadores entre 10 e 14 anos e $64 \%$ dos de 15 a 17 anos. É importante destacar, porém, que, entre as crianças e os adolescentes que estudam, a jornada de trabalho cai para 22,7 horas semanais, em média. Quanto à remuneração, o rendimento médio é de 0,27 salário mínimo (SM) na primeira faixa e de 0,89 SM na segunda. Cabe assinalar ainda que $56,8 \%$ da crianças e 
$27,3 \%$ dos adolescentes não recebem qualquer remuneração, uma prática que varia segundo o nível de desenvolvimento da região, sendo mais frequente entre os que trabalham na agricultura (Sabóia,1999).

No que se refere aos efeitos do trabalho sobre a escolarização, os prejuízos citados são a repetência e a evasão. Muitos dos estudos sobre a questão são também baseados em dados agregados e em correlações entre estes, muitas vezes com implicações de causalidade que não são pertinentes. Assim, por exemplo, Ribeiro e Sabóia (1993) citam dois tipos de correlação como evidências de que o trabalho prejudica a escolarização.

A primeira refere-se ao fato de que, tanto no grupo de 10 a 14 como no de 15 a 17 anos, a proporção de alunos com nível de escolaridade adequada era sensivelmente mais elevada entre os jovens que tinham como atividade somente estudar. A implicação aqui é a de que as longas jornadas de trabalho resultariam em cansaço e falta de tempo para estudar, levando à repetência. A segunda correlação mencionada diz respeito à constatação de que as taxas de escolarização caem abruptamente entre os 14 e 15 anos, idade em que também aumenta consideravelmente a participação dos jovens no mercado de trabalho. Neste caso, a implicação seria de que a dificuldade, vivenciada ou apenas antecipada, de conciliar o trabalho com o estudo levaria ao abandono da escola.

O problema com esse tipo de raciocínio é que as correlações encontradas são freqüentemente "espúrias", por não se considerarem outras variáveis correlacionadas às estudadas. É muito provável, por exemplo, que trabalho infanto-juvenil e "fracasso escolar" estejam relacionados não porque o primeiro seja causa do segundo e sim porque ambos são consequiências dos mecanismos excludentes que perpetuam pobre$\mathrm{za}^{4}$ A vinculação entre trabalho precoce e pobreza familiar é sustentada não apenas pelos dados forneci-

${ }^{4}$ É pertinente lembrar que a relação entre pobreza familiar e "fracasso escolar" tem sido de forma consistente encontrada em imensa quantidade de pesquisas realizadas em países dos mais diversos níveis de desenvolvimento, usando dados agregados ou não. dos pelos censos e pelas PNADs, mas por praticamente todos os estudos que se ocupam do tema. Isto não quer dizer que a pobreza seja a única explicação para o trabalho infanto-juvenil. Outras razões, como auto-afirmação, independência econômica e ideologia familiar, têm sido apontadas como motivos que levam os adolescentes a procurar trabalho (ver, por exemplo, Alves, 1991; Alves-Mazzotti, 1998; Justo, 1991; Kappel, 1992; Mata e Dauster, 1991; Rizzini, Rizzini e Holanda, 1996; Sabóia, 1999). Mas nenhum dos autores citados nega ser a pobreza o principal motor do trabalho precoce.

Análises baseadas no Censo de 1990 ilustram com dados numéricos obtidos em escala nacional esta correlação. Esses dados indicam que, em famílias com renda per capita de 1/2 salário mínimo (SM) mensal ou menos, 23\% das crianças e adolescentes de 10 a 14 anos e $54 \%$ dos de 15 a 17 trabalham, enquanto nas famílias com renda per capita de mais de $2 \mathrm{SM}$, a taxa de ocupação é sensivelmente mais baixa (4,5\% entre os primeiros e $30 \%$ entre os últimos). Além disso, nas famílias com renda per capita de até $1 / 4$ de SM, apenas $60 \%$ das crianças de 10 a 14 só estudam, $15 \%$ estudam e trabalham e $12 \%$ só trabalham, nas famílias de mais de $2 \mathrm{SM}$ de renda per capita, essas taxas são, respectivamente, $91 \%, 5 \%$ e $1 \%$ (PNUD/IPEA, 1996).

É importante enfatizar que a constatação da inegável correlação entre trabalho precoce e pobreza não deve induzir à conclusão de que este é um problema familiar, encobrindo o fato de que esta é uma questão social, determinada pelos mecanismos de reprodução das estruturas de classe.

\section{Pobreza, trabalho infanto-juvenil: "fracasso escolar"}

Estudos realizados na década de 1990 indicam que a relação entre trabalho infanto-juvenil e "fracasso escolar" é bem mais complexa do que a que predomina na literatura anterior.

A importância de se considerar os mecanismos 
excludentes que cercam a pobreza, na discussão dos efeitos do trabalho precoce, é evidenciada em um estudo realizado por Barros e Santos (1991). Esse estudo mostra que a chamada "transmissão intergeracional da pobreza" é mais fortemente determinada por certas condições desfavoráveis encontradas nas comunidades pobres que pelo trabalho infanto-juvenil. Com base em uma análise de dados da PNAD, os pesquisadores constataram que, embora haja uma relação significativa entre a idade que o indivíduo começou a trabalhar, a escolaridade alcançada e os rendimentos na idade adulta, a magnitude desses efeitos é atenuada quando são introduzidos controles estatísticos para nível de escolaridade do pai, idade e área de residência. O que é mais relevante para a discussão em pauta, entretanto, é que essa relação deixa de ser significativa quando a análise se restringe a indivíduos cujos pais têm baixo nível de escolaridade (antigo primário ou menos). Os autores concluem que, dada a ausência de boas oportunidades de estudo e trabalho para as pessoas residentes em áreas pobres, não se pode analisar as conseqüências do trabalho precoce desconsiderando esses outros fatores.

A mediação das condições desfavoráveis que perpetuam a pobreza na discussão dos efeitos do trabalho precoce sobre a escolarização é também evidenciada em um estudo realizado por Levison (1993). Essa autora analisou e comparou dados sobre a defasagem série/idade de alunos trabalhadores e não trabalhadores e concluiu que não há relação direta entre participação no mercado de trabalho e atraso escolar, uma vez que os efeitos negativos sobre a frequiência à escola e o desempenho escolar tendem a ser mais negativos nas áreas mais pobres.

A idéia de que o trabalho infanto-juvenil é o principal responsável pela evasão escolar é também questionada por algumas pesquisas recentes. Estudo de Spindel (citado por Rizzini, Rizzini e Holanda, 1996), com base em dados da RAIS, concluiu que o trabalho não é o motivo mais alegado para o abandono da escola. Outras razões, como distância da escola, falta de vaga e, principalmente, situações ligadas ao próprio sistema de ensino, no que se refere à organiza- ção, conteúdo e didática, são mais freqüentemente mencionadas.

Perissé (1994) chega a conclusões muito semelhantes. Essa autora pesquisou, com pais e alunos de um Centro Integrado de Educação Pública (CIEP), os motivos para o abandono da escola na $5^{\mathrm{a}}$ série do ensino fundamental. A suposição inicial era de que a evasão estava relacionada ao ingresso no mercado de trabalho, uma vez que se tratava de uma escola de horário integral, o que não permitia que os alunos conciliassem escola e trabalho. Os motivos alegados, porém, foram outros. Os alunos haviam abandonado a escola justamente porque as expectativas quanto ao que a escola de tempo integral deveria oferecer não se cumpriram: muitas das disciplinas e atividades inicialmente planejadas foram suprimidas, deixando os alunos ociosos por grandes períodos de tempo. A grande maioria deles rematriculou-se em escolas de tempo parcial e apenas dois alunos estavam trabalhando na época.

Em uma de nossas pesquisas (Alves-Mazzotti, 1998), procuramos ouvir crianças e adolescentes que estudam e trabalham e seus pais sobre as relações entre trabalho precoce e desempenho escolar. Os resultados indicaram que a quase totalidade dos entrevistados acha que o trabalho não interfere nos estudos. Nenhum dos alunos considera seu rendimento ruim: a maioria o considera bom (50\%) ou médio (28\%), $8 \%$ dizem ter um rendimento muito bom e $14 \%$ não sabem avaliar. Também os pais, em sua grande maioria, acham que o trabalho não interfere no rendimento escolar de seus filhos, e alguns chegam mesmo a dizer que há uma influência positiva, pois eles melhoraram na escola depois que começaram a trabalhar. O rendimento dessas crianças é considerado muito bom por $17 \%$ dos pais, bom por $34 \%$, médio por $45 \%$, e apenas um pai avalia que seu filho tem baixo rendimento. Mesmo quando admitem que seus filhos estão tendo dificuldades em alguma matéria, afirmam que "ele nunca gostou mesmo de estudar" ou então que outra circunstância, que não o trabalho, interferiu no rendimento.

As relações entre trabalho precoce e "fracasso 
escolar" foram também focalizadas por Paparelli (2001), que conduziu uma pesquisa com alunos multirrepetentes, seus pais e professores. Essa autora concluiu que "as marcas deixadas nos adolescentes pelas suas histórias de fracasso escolar são motivadoras não só do desejo de abandonar os estudos, como de começar a trabalhar" (p. 166). Entre essas marcas destaca a convivência humilhante com colegas de classe muito mais novos, as práticas agressivas de disciplinamento, as relações conflituosas com os professores, o cotidiano escolar destituído de sentido. Essa autora ressalta, ainda, que as recentes reformas educacionais que procuraram regularizar o fluxo e prolongar a permanência do aluno no sistema escolar por meio de uma política de não reprovação produziram mecanismos de exclusão mais sutis: da "eliminação brutal", representada pela evasão nas primeiras séries do ensino fundamental, decorrente de repetidas reprovações, passou-se à “eliminação suave”, como, por exemplo, o encaminhamento dos "defasados" ao ensino supletivo, que lhes oferece ensino de pior qualidade. Segundo Paparelli, essa lógica excludente arraigada no sistema escolar mantém-se à custa de intenso sofrimento psíquico de professores e alunos.

Em resumo, as pesquisas aqui brevemente relatadas indicam que efeitos atribuídos ao trabalho infanto-juvenil freqüentemente camuflam a atuação de outros fatores a ele correlacionados e não controlados pelas pesquisas, os quais são em parte ou totalmente responsáveis pelos efeitos observados. A carência de boas escolas nas áreas mais pobres, os conteúdos escolares distanciados da realidade das crianças que vivem nessas áreas, a falta de perspectivas para a continuidade dos estudos levam à repetência e à evasão, contribuindo significativamente para o ingresso precoce no mercado de trabalho. Inverte-se, assim, o sentido da relação entre "fracasso escolar" e trabalho infanto-juvenil que prevalece na literatura. Como observa Madeira (1993, p. 78), "a insistência em permanecer numa escola na qual não se progride possui um custo econômico e psicológico", com o qual as famílias pobres não podem arcar.

\section{Família, escola e trabalho}

O segundo ponto a ser destacado refere-se aos preconceitos relacionados às famílias pobres e aos seus reflexos no papel atribuído a estas na produção do "fracasso escolar" e no encaminhamento de seus filhos ao mercado de trabalho.

Patto (2000), com base em ampla revisão da literatura sobre "fracasso escolar", mostra que as explicações ao longo da história apresentam diferentes ênfases, destacando-se, entre elas, as deficiências do aluno (de origem médica ou psicológica), os fatores intra-escolares e a carência cultural de seu ambiente; esta última prevalece, ainda que sob diferentes feições, até os nossos dias. Patto considera que nem mesmo o surgimento das teorias crítico-reprodutivistas na década de 1970 alterou esse quadro, uma vez que a apropriação dessa teoria pelos pesquisadores e educadores resultou em várias distorções conceituais e em generalizações indevidas. A análise da literatura atual sobre o tema levou a autora a concluir que muitas das explicações nela presentes baseiam-se mais em estereótipos do que em resultados de pesquisas pautadas por critérios teórico-metodológicos rigorosos. Por desconhecerem o habitus dos variados segmentos das classes populares, os pesquisadores acabam por "preencher esta lacuna com suposições fundadas em preconceitos" (Patto, 2000, p. 155).

A presença de preconceitos e estereótipos com relação às famílias pobres na literatura que trata do "fracasso escolar" também tem sido apontada em outros estudos recentes. Em uma pesquisa sobre formas de organização familiar em um bairro popular da periferia de São Paulo, Mello (1992) destaca a prevalência do que chamou de "aglomerado familiar". Esses aglomerados, resultantes de processos migratórios que rompem com a organização familiar de origem, são parte do esquema de sobrevivência dessas populações, mantendo-se pela dependência afetiva e estabelecendo um sistema de trocas de serviços e de recursos financeiros alicerçado na consciência da pobreza e na prática da solidariedade. Entretanto, segundo essa autora, tais aglomerados, por se distanciarem do mo- 
delo da família nuclear monogâmica, são vistos pelos pesquisadores como "famílias desorganizadas", resultando em atribuições de caráter estigmatizante. Esse preconceito estende-se à literatura sobre desempenho escolar dos alunos oriundos dessas famílias, que considera "a desorganização familiar como a única responsável pelo que essa mesma literatura denomina fracasso escolar e adaptativo das crianças" (p. 127).

Também preocupada com o "fracasso escolar" das crianças dos meios populares, Zago (2000) desenvolveu uma pesquisa voltada para a compreensão dos percursos escolares dessas crianças. Seus resultados indicaram a existência de uma relativa variação na formação desses percursos, levando a autora a confirmar que a compreensão desses itinerários pressupõe o abandono de concepções universalistas que tomam as camadas populares como um conjunto indiferenciado. Embora a autora não utilize o termo, o que está aqui sendo apontado é, mais uma vez, o estereótipo, considerando-se que a homogeinização artificial de um grupo é característica dos processos de estereotipia.

A presença de preconceitos e estereótipos na literatura sobre "fracasso escolar" das crianças pobres é preocupante, na medida em que estes são transmitidos aos professores nos cursos de formação, ajudando a alimentar crenças e a orientar práticas. Isto torna-se mais grave quando se sabe que preconceitos e estereótipos constituem importantes mediadores da exclusão (Jodelet, 1999).

De fato, esses mesmos estereótipos com relação às famílias pobres estão também presentes no discurso dos professores, como inúmeras pesquisas têm demonstrado. As "mazelas" associadas à pobreza são uma constante, destacando-se, entre estas, a desagregação familiar, a falta de disponibilidade dos pais para cumprir suas funções tradicionais (por incapacidade ou desinteresse), o ambiente desfavorável a que as

\footnotetext{
${ }^{5}$ De acordo com Doise (1991), podemos afirmar que existe um estereótipo social "quando vários membros de um grupo acentuam as diferenças que existem entre os membros de seu grupo e os membros de outro grupo, ao mesmo tempo em que acentuam as semelhanças entre os membros desse outro grupo" (p. 310).
}

crianças estão expostas e as suas precárias condições de saúde, as quais exigiriam atendimento médico e psicológico para que pudessem aprender. A família é responsabilizada não apenas por não dar assistência ao aluno - no sentido de oferecer um acompanhamento individualizado nas tarefas escolares -, mas também por contribuir para o desinteresse pela escola, na medida em que não estimula nem cobra dos filhos um bom desempenho escolar. Sem estímulo e sem apoio familiar, as crianças iniciam sua trajetória de "fracassos" que culmina com o encaminhamento para o trabalho.

A imagem monolítica e preconceituosa construída pelos professores a respeito das famílias pobres também se evidencia na maneira como se expressam com relação ao trabalho infanto-juvenil e ao papel dos pais na inserção precoce. Resultados obtidos em uma de nossas pesquisas (Alves-Mazzotti, 1998) ilustram esse ponto. A pesquisa investigou as representações do trabalho infanto-juvenil apresentadas por professores de escolas públicas de ensino fundamental, comparando-as com as de seus alunos que trabalham, com as de seus pais e empregadores. Os resultados indicaram que, ao compararem seus alunos que trabalhavam com os que não trabalhavam, os professores apontaram diferenças mais favoráveis $(67 \%)$ aos meninos trabalhadores, destacando a maior auto-estima, o senso de responsabilidade e o melhor rendimento geral. Também, ao serem indagados especificamente sobre a relação entre o fato de o aluno trabalhar e o seu desempenho na escola, apenas $31 \%$ dos professores consideram-na negativa (mencionando o cansaço e menos tempo para estudos); os demais consideram-na positiva ou inexistente. Contraditoriamente, porém, enquanto os pais, os empregadores e os próprios meninos apresentam representações positivas e muito semelhantes sobre o trabalho infanto-juvenil - como ajuda à família, que torna as crianças mais responsáveis e as protege dos perigos da rua -, os professores transmitem uma visão francamente negativa, como perda da infância e exploração e humilhação.

A análise dessa dissociação entre o aluno que trabalha e o trabalho do aluno exige alguns esclare- 
cimentos. Inicialmente, cabe mencionar que quase um terço dos professores entrevistados sequer sabia quais eram os alunos que trabalhavam, tendo obtido essa informação no momento da entrevista. Além disso, a maioria deles afirmou que os alunos falam muito pouco ou nada sobre o trabalho, o que nos levou a concluir que os professores contam com escassa ou nenhuma informação concreta sobre o trabalho dessas crianças. Assim, a dissociação observada pode ser explicada pelo fato de que a construção ativa, característica dos processos representacionais, só é possível quando se tem um mínimo de interação com o objeto da representação. Quando estas não existem, a intervenção das ideologias é maximizada. No caso presente, os professores têm a vivência cotidiana com a criança mas não com seu trabalho, o que faz com que tenham de preencher esse vazio com "representações hegemônicas" do objeto (Moscovici, 1988), isto é, representações muito cristalizadas, ou mesmo estereotipadas, adotadas pelo grupo, mas não produzidas por ele.

O mesmo ocorre com a visão que os professores transmitem sobre as famílias dos meninos que trabalham. Apesar de dizerem que elas são ausentes e desinteressadas (significando que não mantêm contato com a escola), os professores têm muitas opiniões sobre eles, em sua maioria (63\%) negativas. A imagem apresentada corresponde à visão prevalente na classe média, segundo a qual os pais das crianças que trabalham são desinteressados do futuro destas, exploradores, desempregados crônicos e indolentes, que empurram os filhos para o trabalho para que estes os sustentem.

No entanto, constatamos que a maior parte das famílias incluídas na pesquisa mencionada era estruturada e completa, com pai, mãe e filhos morando juntos. Na época da entrevista, os pais estavam todos trabalhando, embora em profissões pouco rentáveis (como as de pintor de paredes, servente, pedreiro, carpinteiro, garçon, motorista, zelador de prédio, segurança). Quanto às mães, a maioria (55\%) exercia a profissão de empregada doméstica. Todos apresentavam razoável estabilidade no trabalho, embora nem sempre exercendo a mesma profissão, o que é comum em se tratando de trabalhadores pouco qualificados. Quanto ao uso do dinheiro, $50 \%$ dos pais disseram que os filhos gastavam tudo que ganhavam com suas próprias despesas, notadamente em vestuário e lazer e, também, em material escolar. Dos que ajudavam nas despesas da casa, $32 \%$ o faziam regularmente, com cerca de metade de seus ganhos, enquanto $18 \%$ davam apenas uma ajuda eventual. Todos os pais sabiam informar onde seus filhos trabalhavam e o que faziam. Demonstrando cuidado com os filhos, procuraram empregá-los com pessoas de suas relações ou, quando isto não acontecia, ficavam atentos às suas condições de trabalho e ao tratamento que recebiam. Em sua quase totalidade (93\%), eles afirmaram estar satisfeitos porque os filhos estavam trabalhando e consideravam que eles também estavam satisfeitos. Cabe assinalar que todas essas informações foram confirmadas, em entrevistas individuais, pelas próprias crianças e adolescentes.

Esse perfil das famílias dos jovens trabalhadores, como se vê, não corresponde àquele apresentado pelos professores. Tais representações parecem fortemente influenciadas pelos meios de comunicação os quais focalizam o trabalho infantil em condições subumanas (nos canaviais, nas minas de carvão, na colheita do sisal e em outras atividades semelhantes), mostrando crianças massacradas pela exploração de pais e patrões, o que não é o caso dos alunos desses professores. É provável também que essas representações sejam influenciadas pela produção acadêmica, que, por tratar o trabalho infanto-juvenil como uma categoria homogênea, caracteriza-o de um modo necessariamente negativo, no qual a família aparece ou como conivente com a reprodução das relações sociais inerente ao modo de produção capitalista, ou ela própria como exploradora de seus filhos.

$\mathrm{Se}$, de um lado, em grande parte dos casos, a utilização da mão-de-obra infanto-juvenil é, de fato, marcada por uma mais-exploração - o que torna necessária a denúncia de suas condições de trabalho -, de outro, é também forçoso reconhecer que nem todos os pais são exploradores e nem todo trabalho de crianças 
e adolescentes é penoso. A não consideração da natureza do trabalho exercido pelas crianças e adolescentes, outro sério problema da pesquisa sobre as relações entre trabalho infanto-juvenil e "fracasso escolar", será ilustrada a seguir.

\section{Heterogeneidade do trabalho infanto-juvenil}

Grande parte dos estudos, principalmente os que se baseiam em análises de dados agregados, apresentam o trabalho infanto-juvenil como se fosse uma categoria homogênea; conseqüentemente, são incapazes de distinguir os efeitos de diferentes condições de trabalho sobre o desempenho escolar e o futuro do jovem trabalhador.

Uma pesquisa sobre a representação de trabalho construída por vários grupos de meninos e meninas trabalhadores (Alves-Mazzotti, 1994) ilustra este ponto. Verificou-se que os jovens que exercem atividades não penosas (mensageiros, entregadores de mercadorias, "boleiros" etc.) vêem suas famílias como solidárias - o que pressupõe laços afetivos entre seus membros e esforço partilhado para assegurar a sobrevivência - e têm uma representação positiva do trabalho, considerando-o uma necessidade ligada ao seu próprio sustento e à ajuda à família. Isto reflete-se favoravelmente em sua auto-imagem, fazendo que se sintam competentes e úteis e contribuindo para que se sintam capacitados para enfrentar o futuro. Em contraste com esses resultados, outro grupo, composto por vendedores ambulantes e "flanelinhas", vê suas famílias como desunidas e exploradoras e tem sobre o trabalho uma representação negativa, encarando-o como algo cansativo e penoso. A atividade que desenvolve é associada a frustrações e humilhações, uma vez que, por oferecer serviços e produtos nos quais as pessoas, em geral, não estão interessadas, é frequentemente repelido com aspereza. Essas interações minam a autoestima dos adolescentes fazendo com que se sintam numa situação de "pedintes", o que contribui para uma visão negativa do futuro. Considerando-se o alto custo emocional que essa atividade envolve, bem como seus parcos benefícios, os quais vão em parte ou inteiramente para compor a renda familiar, não surpreende que eles vejam suas famílias como exploradoras.

A representação que o jovem constrói sobre seu próprio trabalho é, portanto, fortemente associada à natureza da atividade e à representação que ele tem sobre sua família. Mais especificamente, a representação que ele constrói sobre o trabalho que exerce no momento, e futuramente sobre o trabalho em geral, é produto de vários fatores inter-relacionados, entre os quais se destacam a maneira como se dá a sua inserção no mundo do trabalho, o destino dos ganhos obtidos e as condições em que exerce suas atividades, os quais, por sua vez, são determinados pela dinâmica das relações na família e sua ideologia com relação ao trabalho.

Este último ponto nos leva a uma última questão importante para a discussão do trabalho infanto-juvenil: o conflito de ideologias entre, de um lado, muitos pesquisadores e professores e, de outro, os segmentos menos favorecidos da população. $\mathrm{O}$ desconhecimento, por parte dos primeiros, dos sentidos e valores atribuídos pelos últimos ao trabalho infanto-juvenil, bem com a outras representações a ele associadas, como, por exemplo, a de infância e a de escola, leva à adoção das representações estereotipadas encontradas na literatura especializada e no discurso dos professores.

Nossos estudos sobre representações do trabalho infanto-juvenil (Alves, 1991; Alves-Mazzotti, 1994, 1998, 2001) têm consistentemente indicado que este é visto pelos pais principalmente como uma forma de ocupação do tempo ocioso de seus filhos, que os protege contra os perigos da rua. Cabe lembrar que a quase totalidade das famílias pobres dos grandes centros urbanos mora em favelas ou em bairros de periferia urbana, onde a violência dos bandidos e da polícia, bem como a tentação representada pelos ganhos auferidos no tráfico de drogas, justificam a preocupação dos pais. O trabalho das crianças e adolescentes é também visto pelos pais como uma ajuda à família ajuda que, como observou Dauster (1991), nas famílias pobres, é considerada "natural", como uma atitude de reciprocidade pelo que o menor recebe da família. 
É considerada também uma forma de socialização que não se opõe à escola, mas a complementa. O sentido atribuído ao trabalho infanto-juvenil pelas classes trabalhadoras está, portanto, associado às funções familiares de proteção e de preparação dos filhos para o futuro, embora, dadas as vicissitudes a que são submetidas, estas funções expressem-se de formas distintas das encontradas nas classes mais favorecidas.

Tais vicissitudes, em certa medida, afetam as representações de criança e de infância, as quais variam ao longo da história e também diferem entre si numa mesma época em função do meio social, como indicam os estudos realizados por Chombart de Lauwe e Feuerhahn (1989). Com base em documentos históricos e produções artísticas de diversas épocas, as autoras analisaram a evolução dessas representações mostrando que, a partir da segunda metade do século XIX, a criança aparece na literatura como um personagem cada vez mais freqüente. Escritores e, mais tarde, cineastas, passam a transmitir uma representação idealizante da infância, investindo-a dos valores dos quais ela se torna símbolo. Mais do que um ser em desenvolvimento, tendo características próprias mas transitórias, a criança tende a ser apresentada como tendo uma "natureza" à parte: projeção dos desejos da sociedade, a ela são atribuídos os valores que permitem contestar o mundo dos adultos. As autoras alertam, entretanto, que, se parece possível fazer algumas generalizações a respeito da criança, cada grupo a representa segundo as normas que lhe são úteis, como os estudos históricos e transculturais têm demonstrado.

É muito provável, portanto, que as famílias social e economicamente desfavorecidas tenham uma representação de infância diferente daquela dos estratos médios da população, em função das restrições a elas impostas e das limitadas alternativas de que dispõem para exercer suas funções tradicionais. Tais contradições levaram Dauster (1991) a concluir que a construção social do fracasso escolar opera na relação entre a criança que tem uma "infância de curta duração" e uma escola que tem como modelo a "infância de longa duração", o que resulta, nas relações sociais que se estabelecem, na "escola de curta duração".

\section{Considerações finais}

A visão de mundo que as crianças vão progressivamente formando, bem como a representação que fazem de si mesmas, resulta das interações e práticas cotidianas, nas quais elas apreendem uma massa considerável de informações, imagens e valores. Nesse processo, os aspectos relevantes da realidade física e social são por elas interpretados em razão das representações desses objetos, comunicadas pelos adultos que desempenham papéis significativos em sua vida, como é o caso de suas famílias e de seus professores.

$\mathrm{O}$ desconhecimento das diversas formas assumidas pelo trabalho infanto-juvenil e, principalmente, dos diferentes sentidos atribuídos a este pelas classes trabalhadoras faz com que os professores apresentem representações estereotipadas e fortemente negativas no que se refere ao trabalho de seus alunos e às suas famílias. Ao serem apreendidas pelos jovens trabalhadores, tais representações entram em conflito com a valorização de seu trabalho prevalente em seu meio social, o que tem repercussões cognitivas e afetivas sobre os próprios alunos, na medida em que criam tensões e desconfianças no âmbito familiar e minam sua auto-estima, ao desqualificar o que para eles é motivo de orgulho. Não podemos esquecer que as representações têm uma função identitária (Abric, 1994), isto é, o universo representacional do sujeito define sua identidade, seus grupos de pertença e, em contrapartida, os grupos dos quais se sente excluído ou que ele próprio rejeita. Nossas pesquisas com crianças e adolescentes trabalhadores têm consistentemente indicado que ser um jovem trabalhador torna-se uma parte essencial de sua identidade. Assim, ao desqualificar seu trabalho e sua família, desqualifica-se também o próprio aluno.

Cabe enfatizar que as representações não são palavras ao vento; elas concretizam-se em práticas e veiculam sentidos e valores. Assim, por exemplo, o fato de os professores verem o trabalho de seus alunos como exploração por parte de suas famílias e uma humilhação para eles faz que evitem falar ou mesmo ouvir o que esses alunos falam sobre o assunto, con- 
forme declararam nas entrevistas realizadas que constam em uma de nossas pesquisas (Alves-Mazzotti, 1998). O constrangimento que os professores projetam no comportamento deles transmite ao aluno uma visão negativa que pode ter graves conseqüências no futuro, não importa o que esses professores eventualmente venham a dizer sobre o valor do trabalho ou a importância dos laços familiares. Além disso, a deliberada ignorância de uma parte tão importante da vida dessas crianças, bem como dos valores e necessidades da classe trabalhadora, impede que os professores realizem a tão propalada integração entre a educação oferecida e a realidade dos alunos, de modo que torne a escola mais atraente e eficaz para essa população.

Finalmente, não é ocioso ressaltar, mais uma vez, que não estamos aqui defendendo o trabalho infantojuvenil. Não desconhecemos o fato de que grande parte das crianças e adolescentes pobres é submetida a condições de trabalho penosas, insalubres, humilhantes, além de serem vilmente explorados por seus patrões. Não desconhecemos também o fato de que, embrutecidos, desumanizados, pelas condições de vida a que eles próprios foram submetidos, muitos pais são coniventes ou mesmo agentes dessa exploração. O que procuramos ressaltar neste artigo é o fato de que nem todo trabalho infanto-juvenil é penoso, insalubre ou humilhante, nem todos os pais são exploradores, e que a homogeneização que leva à estereotipia, muitas vezes se passando por uma posição crítica, é, na verdade, excludente. Ao atribuir às famílias pobres o "fracasso escolar" de seus filhos, mascara-se a inadequação do sistema escolar para atender às necessidades dessas crianças; ao culpar essas famílias pelo trabalho precoce, mascara-se também o fato de que são, elas próprias, vítimas dos mecanismos sociais perpetuadores da pobreza. Em ambos os casos, contribui-se para que as raízes da questão permaneçam intocadas.

Não queremos, com isso, atribuir aos professores a culpa por esse mascaramento, omitindo o peso de processos sociais mais amplos. Não cabe aqui analisar em detalhe as motivações dos professores, mas certamente suas representações sobre as famílias de seus alunos têm a ver com seu lugar social e com sua identidade, uma vez que essas representações são largamente partilhadas em seus grupos de pertença. Mais especificamente, ao responsabilizarem as famílias pobres pelo "fracasso escolar" de seus filhos, os professores tentam manter uma identidade profissional positiva, exorcizando sua própria participação nesse "fracasso". Também no que se refere ao trabalho infanto-juvenil, o sociocentrismo dos professores e dos pesquisadores da educação impede-os de ver que, de um lado, nem sempre os pais têm escolha, e, de outro, muitas vezes essa escolha é ditada por motivos diversos daqueles que lhes são atribuídos. Toma-se por descaso uma atitude que, como vimos, pode ser movida pela preocupação com o presente e o futuro dos filhos.

É nesse sentido que o conhecimento das representações do trabalho infanto-juvenil construídas pelos pequenos trabalhadores e por pais, professores e formadores de opinião, e suas consequiências sobre as práticas e sobre as representações que as crianças têm de si mesmas, de sua família e de sua cultura, constituem referência essencial para a reflexão sobre as políticas e as práticas voltadas para a questão.

ALDA JUDITH ALVES-MAZZOTTI, doutora pela New York University, é professora titular de psicologia da educação da UFRJ (aposentada) e atualmente coordenadora do Mestrado em Educação da Universidade Estácio de Sá. Principais publicações: $O$ método nas ciências naturais e sociais: pesquisas quantitativas e qualitativas, em co-autoria com Fernando Gewandsznajder (São Paulo: Editora Pioneira, 2001, 2ª reimpressão); Relevância e aplicabilidade da pesquisa em educação (Cadernos de Pesquisa, São Paulo, Fundação Carlos Chagas/Cortez, nº 113, p. 39-50, jul. 2001); Trabalho infanto-juvenil: representações de meninos trabalhadores, seus pais, professores e empregadores (In: MOREIRA, Antonia Silva Paredes; OLIVEIRA, Denize Cristina, org.), Estudos interdisciplinares em representações sociais (Goiânia: AB Editora, 1998, p. 285-302). Pesquisa atual, apoiada pelo CNPq: Trabalho infanto-juvenil e "fracasso escolar": representações de alunos repetentes, trabalhadores e não trabalhadores, e de seus professores. E-mail: aldamazzotti@uol.com.br. 


\section{Referências bibliográficas}

ABRIC, J.C., (1994). Représentations sociales: aspects théoriques. In: (org.). Pratiques sociales et représentations. $\mathrm{Pa}-$ ris: Presses Universitaires de France.

ALVES, A. J., (1991). Meninos de rua e meninos na rua: estrutura e dinâmica familiar. In: FAUSTO, A., CERVINI, R., (org.). $O$ trabalho e a rua: crianças e adolescentes no Brasil urbano dos anos 80. São Paulo: Cortez.

ALVES-MAZZOTTI, A. J., (1994). Do trabalho à rua: uma análise das representações sociais produzidas por meninos trabalhadores e meninos de rua. In: VÁRIOS AUTORES. Tecendo saberes. Rio de Janeiro: Diadorim, Jornada de Pesquisadores em Ciências Humanas do Centro de Filosofia e Ciências Humanas da UFRJ.

,(1997). Representações sociais dos "meninos de rua". Revista Educação e Realidade, v. 22, n. 1, p.183-207.

, (1998). Trabalho infanto-juvenil: representações de meninos trabalhadores, seus pais, professores e empregadores. In: MOREIRA, A. S. P., OLIVEIRA, D. C., (orgs.). Estudos Interdisciplinares em Representações Sociais. Goiânia: AB Editora. p. 285-302.

, (2001). Representações de professores sobre o "fracasso escolar”. II Jornada Internacional sobre Representações Sociais, Florianópolis, 19 a 22 de setembro, Anais.

ALVIM, M. R. B., VALLADARES, L., (1988). Infância e sociedade no Brasil: uma análise da literatura. BIB - Boletim Informativo e Bibliográfico de Ciências Sociais, nº 26, p. 3-37.

BARROS, R., SANTOS, E.C., (1991). Conseqüências de longo prazo do trabalho precoce. In: FAUSTO, A., CERVINI, R., (ed.). O trabalho e a rua: crianças e adolescentes no Brasil urbano dos anos 80. São Paulo: Cortez.

BRASIL, (1991). Estatuto da Criança e do Adolescente. Brasília: Presidência da República.

CERVINI, R., BURGER, F., (1991). O menino trabalhador no Brasil urbano dos anos 80. In: FAUSTO, A., CERVINI, R., (ed.). O trabalho e a rua: crianças e adolescentes no Brasil urbano dos anos 80. São Paulo: Cortez.

CHOMBART DE LAUWE, M .J., FEUERHAHN, N., (1989). La représentation sociale dans le domaine de l'enfance. In:
JODELET, D., (ed.). Représentations sociales: un domaine en expansion. Paris: PUF.

DAUSTER, T., (1991) Uma infância de curta duração; o significado simbólico do trabalho e da escola e a construção social do "fracasso escolar" nas camadas populares urbanas. Educação, n 3, Rio de Janeiro: PUC-Rio, Departamento de Educação.

DOISE, W., (1991). Las relaciones entre grupos. In: MOSCOVICI, S. (org.). Psicologia social. Barcelona: Paidós, v. 1.

IBGE, (2000). Anuário Estatístico do Brasil, 1999. Rio de Janeiro: Instituto Brasileiro de Geografia e Estatística, 2000.

JODELET, D., (1999) Os processos psicossociais da exclusão. In: SAWAIA, Bader, (org.). As artimanhas da exclusão: Análise psicossocial e ética da desigualdade social. Petrópolis: Vozes.

JUSTO, I. V. S., (1991). Crianças e adolescentes no mercado de trabalho: socialização ou exploração? Dissertação de Mestrado. PUC-Rio.

KAPPEL, M. D. B., (1992). A situação do estudante trabalhador e sua apreensão via pesquisa domiciliar: revisão conceitual metodológica e sugestões para seu desenvolvimento. Dissertação de Mestrado. PUC-Rio, Departamento de Educação.

LEVISON, D., (1993). O trabalho e a escolarização de crianças e adolescentes nas cidades brasileiras. Minneapolis: Center for Population Analysis, University of Minnesota.

MADEIRA, F.R., (1993). Pobreza, escola e trabalho: convicções virtuosas, conecções viciosas. São Paulo em Perspectiva, v. 7 , $\mathrm{n}^{\mathrm{o}} 1$, p.70-83, jan./mar.

MATA, M. L., DAUSTER, T., (1991). O valor social da educação e do trabalho em camadas populares urbanas. Relatório de pesquisa. PUC-Rio, Departamento de Educação.

MELLO, S. L., (1992). Classes populares, família e preconceito. Psicologia USP, São Paulo, v. 3, nº 1/2, p. 123-130.

MOSCOVICI, S., (1988). Notes towards a description of social representations. European Journal of Social Psychology, v. 18, p. 211-250.

O GLOBO, (2001). Caderno Especial Retratos do Brasil, Rio de Janeiro, 20 dez., p. 3-6

PAPARELLI, R., (2001). Trabalho precoce e escolarização. Dissertação de Mestrado. São Paulo, USP, Instituto de Psicologia.

PATTO, Maria Helena Souza, (2000). A produção do fracasso 
escolar: histórias de submissão e rebeldia. São Paulo: Casa do Psicólogo.

PERISSÉ, V. L. S., (1994). Análise da evasão de alunos de um CIEP de segundo segmento do primeiro grau para escolas de horário parcial. Dissertação de Mestrado. Rio de Janeiro, UFRJ, Faculdade de Educação.

PNUD/IPEA, (1996). Relatório sobre o desenvolvimento humano no Brasil. Brasília.

RIBEIRO, R. M., SABÓIA, A. L., (1993). Crianças e adolescentes na década de 80: condições de vida e perspectivas para o terceiro milênio. In: RIZZINI, I. (org.). A criança no Brasil hoje: desafio para o terceiro milênio. Rio de Janeiro: Editora Universitária Santa Úrsula.

RIZZINI, I, RIZZINI, I., HOLANDA, F. R. B., (1996). A criança e o adolescente no mundo do trabalho. Rio de Janeiro: Editora Universitária Santa Úrsula.

SARTI, C. A., (1999). As crianças, os jovens e o trabalho. In: WESTPHAL, M., (org.). O compromisso da saúde no campo do trabalho infanto-juvenil: proposta de atuação. São Paulo: USP, Faculdade de Saúde Pública.

SABÓIA, A. L., (1999). Situação do trabalho infanto-juvenil na metade dos anos 90. O Social em Questão, Rio de Janeiro, PUCRio, Departamento de Serviço Social, v. 3, $\mathrm{n}^{\circ}$ 3, p. 35-51.

ZAGO, Nadir, (2000). Processos de escolarização nos meios populares: as contradições da obrigatoriedade escolar. In: NOGUEIRA, M. A., ROMANELLI, G., ZAGO, N. (org.). Família e escola: trajetórias de escolarização em camadas médias e populares. Petrópolis: Vozes. 
as emoções. As chamadas terapias alternativas são propostas para lidar com as emoções, juntamente com a teoria do apoio social. Esta teoria propõe que quando pessoas recebem apoio emocional ou material sistemático de grupos ou instituições, este apoio é benéfico para a saúde dessas pessoas. A hipótese levantada é que o custo das terapias alternativas, juntamente com as dificuldades do sistema público de saúde em lidar com os sofrimentos dos pobres, ajuda a explicar o grande crescimento das igrejas pentecostais e evangélicas em torno das classes populares no Brasil.

Palavras-chave: pobreza, saúde e emoção, pentecostalismo.

Poverty, emotion and health: a discussion on Pentecostalism and health in Brazil

In the field of health and education, a debate has arisen about the causes of health problems. This debate maintains that the origin of health problems today is basically related to the emotions rather than viruses or bacteria. The theory of social support suggests that if the causes of health problems are basically emotional, then the solutions must also be related to the emotions. The so-called alternative therapies are proposed as a way of dealing with the emotions, together with the theory of social support. This theory holds that when people receive systematic emotional or material support from groups or institutions, this support is beneficial to their health. This raises the hypothesis that the cost of alternative therapies together with the difficulties encountered in the public health system in dealing with the sufferings of the poor help to explain the enormous growth of Pentecostal and evangelical churches among working-class populations in Brazil.
Key-words: poverty, emotion and health, Pentecostalism.

\section{Ana Lúcia Valente}

\section{Os negros, a educação e as políticas}

\section{de ação afirmativa}

Este texto procura avançar na compreensão do movimento histórico que subjaz a implementação de políticas de ação afirmativa para os negros no campo educacional, considerando ser essa a condição para o atendimento dos interesses e necessidades desse grupo, na perspectiva da transformação. Para isso, são retomadas reflexões realizadas em outras oportunidades, explicitando idéias há muito debatidas por estudiosos e militantes negros, bem como discutindo os momentos em que as diferenças são transformadas em "problema", quando são marcas distintivas e necessárias da condição humana. Em seguida, busca-se avaliar as condições materiais e ideológicas do capitalismo atual, o processo de etnicização da força de trabalho e o deslocamento do debate para a esfera cultural/ educacional promovido por organismos internacionais.

Palavras-chave: negros e educação, políticas de ação afirmativa.

\section{Negroes, education and policies of affirmative action}

This text seeks to further our understanding of the historical movement which underlies the implementation of policies of affirmative action for Negroes in the field of education considering this to be the condition for attending the interests and needs of this group, in the perspective of transformation. To this end, the text takes up reflections developed on other opportunities explaining ideas debated for years by scholars and militant Negroes and discussing the moments in which differences are transformed into a "problem", when they are in fact distinctive and necessary marks of the human condition. Thereafter, we seek to evaluate the material and ideological conditions of present day capitalism, the process of 'ethnicisation' of the work force and the dislocation of the debate from the cultural/ educational sphere promoted by international organisations.

Key-words: negroes and education, policies of affirmative action.

Alda Judith Alves-Mazzotti

Repensando algumas questões sobre o trabalho infanto-juvenil

$\mathrm{O}$ artigo focaliza algumas questões presentes na discussão acadêmica sobre o trabalho infanto-juvenil e suas consequiências sobre o "fracasso escolar" das crianças pobres, buscando apontar posicionamentos ideológicos, sociocentrados, e falhas metodológicas que levam à redução da complexidade do problema. Tal redução evidencia-se no estabelecimento de relações lineares que desconsideram as mediações envolvidas, bem como na homogeneização de categorias que incluem uma vasta gama de variações internas. São apresentados exemplos de pesquisas que sustentam os questionamentos feitos, apontando-se algumas consequiências daqueles posicionamentos reducionistas sobre as práticas escolares e o desenvolvimento cognitivo e afetivo das crianças e adolescentes trabalhadores. Dentre os fatores que precisam ser considerados na discussão das relações entre trabalho precoce e trajetória escolar são destacados: as mediações representadas pelas diversas instâncias excludentes que cercam a pobreza, a heterogeneidade do trabalho infanto-juvenil e o papel atribuído às famílias pobres com relação ao 
"fracasso escolar" e ao trabalho precoce de seus filhos.

Palavras-chave: fracasso escolar, trabalho infanto-juvenil, relação família/escola, representações sociais

Rethinking some questions related to child and adolescent labour

The article focuses on issues related to the academic discussion on child and adolescent labour and its consequences for the "school failure" of disadvantaged children, seeking to identify socially centred ideological positions and methodological flaws that lead to a reduction in the complexity of the problem. Evidence of this reduction is to be found in two false assumptions: a) a linear relation between the variables, ignoring the mediations involved; and $b$ ) $a$ homogenisation of those categories, disregarding the vast array of internal variations. Research supporting this questioning is presented, indicating some of the consequences of those reductionist postures on school practices and on the cognitive and affective development of underage workers. Among those factors that need to be considered in the discussion of the relations between early work and school trajectory, the following are stressed: the mediations represented by the diverse instances of exclusion that perpetuate poverty, the heterogeneity of child and adolescent work, and the role attributed to poor families with regard to "school failure" and to early insertion of their children in the world of work.

Key-words: school failure, child and adolescent work, family/school relations, social representations.

Rosilda Arruda Ferreira

Política educacional e poder local: análise das repercussões do Programa de Erradicação do
Trabalho Infantil na educação de municípios pernambucanos

A partir de uma reflexão sobre as causas que têm conduzido à propagação do uso da força de trabalho de crianças e adolescentes, este texto apresenta resultados de uma pesquisa em que se analisou o processo de implementação do Programa de Erradicação do Trabalho Infantil (PETI) e as suas repercussões sobre a organização da educação pública em treze municípios pernambucanos, focalizando o período compreendido entre novembro de 1997 a janeiro de 2000. Inicialmente são apresentadas uma caracterização do trabalho infantil no Brasil e a gênese do surgimento do Programa. Em seguida, trata-se da mesma questão em relação a Pernambuco, para, a partir destas contextualizações, apresentarse especificamente os resultados da pesquisa que revelaram a dificuldade do Programa em atingir os objetivos de erradicação do trabalho infantil, garantindo, no entanto, a sua suspensão temporária nos municípios analisados. Quanto aos resultados educacionais, a análise indicou que, apesar dos impactos positivos sobre os índices de evasão escolar, quando se trata dos aspectos pedagógicos muito ainda há por fazer para melhorar a qualidade do ensino e os níveis de aprendizagem dos alunos.

Palavras-chave: política educacional, trabalho infantil, educação municipal.

Educational policy and local power: an analysis of the repercussions of the Programme for the Eradication of Child Labour on education in municipalities in the State of Pernambuco

In this paper, the impact of the implementation of the Programme for the Eradication of Child Labour (PECL) on thirteen cities in the State of Pernambuco, Brazil, is analysed focusing on the period between November 1997 and January 2000. Child labour in Brazil and specifically in the state of Pernambuco is characterised along with a description of how the Programme was created. The results of the research reveal the Programme's difficulties in achieving its goal of eradicating child labour, despite its temporary suspension in those cities under analysis. The educational results reveal that despite the positive impact of the Programme in decreasing the number of school dropouts, in pedagogical terms, efforts are still needed to improve the quality of education and the levels of student learning.

Key-words: educational policy, child labour, municipal education.

Denice Barbara Catani

Luciano Mendes de Faria Filho Um lugar de produção e a produção de um lugar: a história e a historiografia divulgadas no GT História da Educação da ANPEd (1985-2000)

$\mathrm{O}$ texto analisa o percurso do GT História da Educação da ANPEd (19852000), retomando as características das produções divulgadas no grupo e o processo de constituição do mesmo como "lugar de produção" da pesquisa histórico-educacional brasileira. Ressalta o trabalho de articulação do espaço do GT como espaço de discussões teórico-metodológicas e de fortalecimento de novas perspectivas de investigação. Identifica, ainda, nesta análise o aparecimento de perspectivas teóricas e opções metodológicas que marcam a produção nacional na área.

Palavras-chave: história da educação, GT história da educação da ANPEd, história e historiografia da educação, produção histórico-educacional brasileira, história da educação brasileira. 